\title{
Control of polymorphism and morphology in solution sheared organic field-effect transistors
}

\author{
Sergi Galindo ${ }^{\ddagger}$, Adrián Tamayo ${ }^{\ddagger}$,Francesca Leonardi and Marta Mas-Torrent* \\ Institut de Ciència de Materials de Barcelona (ICMAB-CSIC) and Networking Research \\ Center on Bioengineering, Biomaterials and Nanomedicine (CIBER-BBN), Campus de la \\ Universitat Autònoma de Barcelona, Cerdanyola, E-08193 Barcelona, Spain. \\ E-mail: $\underline{\text { mmas@icmab.es }}$
}

${ }^{\ddagger}$ S. G. and A. T. contributed equally to this work.

Keywords: OFETs, solution shearing, polymorphism, morphology, printed electronics

During the last decades, small molecule organic semiconductors have been successfully used as active layer in organic field-effect transistors (OFETs). Despite the high mobility achieved so far with organic molecules, in order to progress in the field it is crucial to find techniques to process them from solution. The device reproducibility is one of the principal weak points of organic electronics for further commercialization. To achieve a high device-to-device reproducibility it is essential to control the morphology and polymorphism of the active layer for OFET application. In this work, we report the preparation of thin films based on blends of the organic semiconductor dibenzo-tetrathiafulvalene (DB-TTF) and polystyrene (PS) by a solution shearing technique compatible with up-scaling. Here, we demonstrate that varying the deposition parameters (i.e., speed and temperature) or the solution formulation (i.e., semiconductor/binder polymer ratio) is possible to control the film morphology and semiconductor polymorphism and, hence, the different intermolecular interactions. We demonstrate that the control of the thermodynamics and kinetics of the crystallization process is key for the device performance optimization. Further, this is the first time that DB-TTF thin films of the $\alpha$-polymorph are reported. 


\section{Introduction}

In thin films of small molecule organic semiconductors (OSCs) the charge transport properties are ruled by the molecular packing in the solid state as well as the film morphology. For this reason, important efforts have been devoted to the preparation of highly crystalline films by improving the fabrication conditions or by interface engineering. ${ }^{[1-5]}$ An additional challenge is the control of polymorphism. This phenomenon is commonly encountered in small molecule OSCs due to the presence of weak van der Waals intermolecular interactions that makes these materials prone to structural modifications. ${ }^{[6,7]}$ The influence of the crystal phase in single crystal organic field-effect transistors (OFETs) has been reported for a few organic materials clearly elucidating that the crystal phase can have a dramatic impact on the device performance. ${ }^{[8-14]}$ In thin films the polymorph control is even more challenging. Typical approaches that have been employed to tune molecular packing in thin films are substrate temperature in vacuum or solution deposited OSCs, ${ }^{[15-18]}$ dielectric modification, ${ }^{[19]}$ solvent modification or solvent post-deposition treatments, ${ }^{[20-22]}$ film thickness $^{[23,24]}$ and, more recently, the modification of the binder polymer nature, ${ }^{[25]}$ kinetic trapping of metastable polymorphs ${ }^{[26,27]}$ and material confinement. ${ }^{[1,28]}$ Currently, there is an increasingly growing interest in developing solution coating techniques compatible to roll-toroll fabrication processes for low cost and large area coverage applications and many significant advances have been achieved in this direction. ${ }^{[29]}$ However, the major challenge of understanding and controlling the formation of a given polymorph as well as ensuring phase purity has been hardly unexplored in these films. Here, using a solution shearing deposition method, namely, bar-assisted meniscus shearing (BAMS), thin films based on blends of the organic semiconductor dibenzo-tetrathiafulvalene (DB-TTF) and polystyrene (PS) (Figure 1) were prepared and applied in OFETs. ${ }^{[30]}$ We found that the influence of the substrate temperature and deposition speed during the deposition process and also the OSC:binder polymer ratio employed have a key role in the thermodynamics and kinetics of the 
crystallization process. As a result, the modification of these parameters strongly affect the final thin film morphology and polymorphism and, in turn, the device characteristics. Understanding the crystallization process in solution-coated thin films provides an important route for achieving high device-to-device reproducibility.

\section{Results and Discussion}

DB-TTF was selected as the active semiconductor. This material has been shown to be a promising organic semiconductor due to its electronic and supramolecular structure. However, DB-TTF is known to exhibit a complex polymorphism scenario, where four polymorphs have already been identified. ${ }^{[31,32]}$ Mobility $(\mu)$ values in the range $0.1-1 \mathrm{~cm}^{2} \mathrm{~V}^{-}$ ${ }^{1} \mathrm{~s}^{-1}$ have been reported for solution-processed single crystals of DB-TTF belonging to the most thermodynamically stable $\alpha$-phase. ${ }^{[33,34]}$ On the other hand, devices comprising vacuumdeposited DB-TTF thin films, characterized as the kinetically more favorable $\gamma$-phase, show field-effect mobilities that range from $10^{-2}$ to $10^{-1} \mathrm{~cm}^{2} \mathrm{~V}^{-1} \mathrm{~s}^{-1} \cdot{ }^{[35-38]} \mathrm{DB}-\mathrm{TTF}$ molecules pack in a herringbone pattern in the $\alpha$ polymorph, while the $\gamma$-phase has only been found in thin films and has not been resolved. ${ }^{[32]}$ It should be also highlighted that typically DB-TTF devices exhibit large threshold voltages $\left(V_{T H}\right)$, higher than $20 \mathrm{~V},{ }^{[33,35,36]}$ and are very unstable in environmental conditions. However, blending the material with an inert polymer has been shown to be an ideal strategy to fabricate stable DB-TTF-based devices. ${ }^{[30,39,40]}$

The BAMS technique was selected to process this material. This is a non-contact technique that consists in pouring a semiconductor/polymer blend solution in between a hot target substrate and a bar forming a confined meniscus. ${ }^{[30,41]}$ As the substrate is displaced, a fast crystallization of the film takes place at the substrate-solution-air interfaces, forming a nanometer-thick film. During the crystallization a vertical phase separation that takes place, forming a bottom PS layer and a top OSC layer with high crystallinity. ${ }^{[30,39,40]}$ In particular, 
we explore here how the speed of the moving substrate and its temperature affect the crystallization process as well as the ratio organic semiconductor/insulating polymer. Remarkably, it should be highlighted that the data reported below are the result of a large statistical study; each value given for a specific experimental conditions has been averaged from at least 42 different measured devices. Further, all the measurements have been performed in ambient conditions.

\section{Substrate Temperature}

The influence of the substrate temperature during the deposition of the active layer on the thin film morphology/crystallinity has been widely investigated, using both the thermal evaporation or drop casting technique. ${ }^{[42-46]}$ However, to our knowledge, there has never been reported a systematic study about the effect of the substrate temperature employing solutionshearing techniques. We prepared $2.5 \%$ weight blend solutions of DB-TTF/PS $\left(\mathrm{M}_{\mathrm{w}}=3000\right.$ $\mathrm{g} / \mathrm{mol}$ ) at a ratio of 1:2 in chlorobenzene (CB). Subsequently OFET devices were prepared by BAMS at a deposition speed of $10 \mathrm{~mm} / \mathrm{s}$ varying the temperature from 25 to $120^{\circ} \mathrm{C}$.

Optical microscopy images of the resulting films are shown in Figure 2. Clearly, the film morphology and crystallinity are highly dependent on the substrate temperature. At low substrate temperatures, needle-shaped DB-TTF crystals are observed (Figure 2a, b), while the films deposited at higher temperatures show plate-like crystalline domains (Figure 2c-f). Note also that holes are found in the films deposited at $120{ }^{\circ} \mathrm{C}$ probably due to the too fast evaporation of the solvent that causes the formation of air bubbles.

The XRD diffractogram of the films prepared at $25^{\circ} \mathrm{C}$ exhibits two sets of peaks (Figure 3). The diffraction peak at $2 \theta$ of $8^{\circ}$, and its reflections, has been assigned at $\alpha$-phase, whereas the peak at $6.5^{\circ}$ to the $\gamma$-phase. ${ }^{[30,32]}$ When the substrate temperature is increased, the amount of 
the $\alpha$-polymorph diminishes, and from $100{ }^{\circ} \mathrm{C}$ and above only the $\gamma$-phase is found. Thus, when the substrate temperature is high the thermodynamic equilibrium is not reached during the deposition process and only the kinetic phase is formed. On the contrary, below $100{ }^{\circ} \mathrm{C}$, the films are still somewhat wet after spreading the solution on the substrate, and then the thermodynamic $\alpha$-phase, previously found in single crystals, ${ }^{[33,34]}$ also coexists with $\gamma$-phase.

The DB-TTF/PS films were explored by atomic force microscopy (AFM) in tapping mode (see Figure S1 for the topographical images) to determine their thickness and roughness (Figure 4). The films deposited at higher temperatures (100 and $120{ }^{\circ} \mathrm{C}$ ) are smoother and thinner than the films where the phase mixture coexists. This can be accounted by the fact that the films with large plate-like crystallites ( $\gamma$-phase) are more homogenous.

Figure 5 shows the transfer characteristics of the transistors prepared from DB-TTF/PS 1:2 $2.5 \%$ wt. solutions and deposited at different substrate temperatures. The corresponding output characteristics are shown in the (Figure S2). Large off-current variations are observed significantly affecting the final device performance. In Figure 6, the principal OFET parameters versus substrate temperature are displayed (see also Table S1). Undoubtedly, the best performance is achieved in devices with the active layer deposited at substrate temperature around $100{ }^{\circ} \mathrm{C}$. For this reason, around this temperature (i.e., 95, 100, 105 and $110^{\circ} \mathrm{C}$ ) more devices were fabricated in order to finely tune the optimal temperature for maximizing the device performance.

Noticeably, only the devices deposited between 95 and $110^{\circ} \mathrm{C}$ reach a mobility above 0.10 $\mathrm{cm}^{2} \mathrm{~V}^{-1} \mathrm{~s}^{-1}$, otherwise the device mobility does not exceed $0.05 \mathrm{~cm}^{2} \mathrm{~V}^{-1} \mathrm{~s}^{-1}$ (Figure 6). Thus, the phase mixture and the grain boundaries between domains of different phases have clearly a 
negative impact on the device performance as observed in the devices prepared at $80{ }^{\circ} \mathrm{C}$ and below. In addition, the lower mobility of the samples deposited at $120^{\circ} \mathrm{C}$ can be attributed to the lower on-state current because of the presence of holes in the layer.

The sub-threshold swing (SS) of the OFETs based on DB-TTF/PS decreases with the substrate temperature (Figure 4, Table S1). A small SS means a fast transition between off- and onstates. The SS can be related to the occupancy of the semiconductor/insulator interface traps. ${ }^{[47]}$ This points that the thin film morphology of the $\gamma$-phase leads to a better interface OSC/dielectric and, in consequence, the number of interface traps is lower. ${ }^{[30]}$ Other parameters to consider are the on/off ratio and the $V_{T H}$. When decreasing the substrate temperature, the on/off ratio rapidly decreases due to the increase of the off-current. This can be explained by unintentional doping. High temperature reduces the amount environmental humidity. Additionally, the less crystalline films with more defects and grain boundaries prepared at lower temperature films are more prone to be doped by oxygen. Accordingly, the $V_{T H}$ decreases exponentially when the substrate temperature increases (Figure 6, Table S1). Considering all above, it can be firmly stated that the optimum substrate temperature for OFETs based on DB-TTF/PS 1:2 $2.5 \%$ wt. is $105^{\circ} \mathrm{C}$.

\section{Coating Speed}

A fast coating speed in solution based techniques arouses the interest of the industry to increase the throughput and in consequence reduce the device production costs. However, the coating speed control influences on the crystallization of the deposited thin film. Hence, most of the high performing reported OFETs fabricated by solution-shearing techniques typically use low rates (i.e., $1-5 \mathrm{~mm} / \mathrm{s}$ ) to ensure material crystallization. ${ }^{[1,48-50]}$ By changing the coating speed, the molecular orientation can also be affected. ${ }^{[51,52]}$ Here, the influence of the 
coating speed on the OFET performance in the DB-TTF/PS films is also investigated. Solutions $2.5 \%$ wt. of DB-TTF/PS in ratio 1:2 are deposited by BAMS at a fixed substrate temperature of $105^{\circ} \mathrm{C}$ and varying the coating speed from 1 to $100 \mathrm{~mm} / \mathrm{s}$.

The prepared thin films were characterized by optical microscopy (Figure 7). The images show a drastic variation on the films morphology. At the coating speed of $1 \mathrm{~mm} / \mathrm{s}$ the layer reveals well-oriented ribbon-shaped crystals, while at higher speeds uniform layers of the plate-like crystallites are observed. At the fastest coating (i.e., $100 \mathrm{~mm} / \mathrm{s}$ ) speed the domain size of these crystallites is reduced.

Interestingly, XRD data reveal that the thin film structure obtained at $1 \mathrm{~mm} / \mathrm{s}$ is the $\alpha$ polymorph, while the $\gamma$-phase is formed at higher coating speeds (Figure 8). It is important to highlight that this is the first time that the DB-TTF $\alpha$-phase is found in a thin film; by growing the film very slowly the thermodynamic phase has been formed. Unexpectedly, films grown at $1 \mathrm{~mm} / \mathrm{s}$ but at lower substrate temperature (i.e., 25 and $60^{\circ} \mathrm{C}$ ) gave films with $\alpha$ and $\gamma$ phase mixture (Figure S3 and Figure S4). Therefore, it is demonstrated that the coating speed does not only influence on the film morphology and degree of crystallinity but can also have a crucial role in determining the semiconductor polymorph.

In Figure 9 the values of thickness, roughness and domain size of the thin films deposited at different coating speed determined by AFM are shown. The AFM topography can be found in Figure S5. Morphologically, we can distinguish three different regions depending on the coating speed. The first region is at the lowest coating speed $(1 \mathrm{~mm} / \mathrm{s})$ where the thickness and roughness are higher. In addition, the domains are small due to high number of nucleation points giving long but very thin crystallites. The coating speeds ranging from 3 to $10 \mathrm{~mm} / \mathrm{s}$ 
give rise to very smooth and thin films characterized by large crystallites. Finally, in the region with coating speeds above $10 \mathrm{~mm} / \mathrm{s}$, the films are thicker and the crystallites size domain smaller, being directly and inversely proportional with the coating speed, respectively. In the plot film thickness vs coating speed a U-shape curve is found in agreement with the three different regimes highlighted in Figure 9. This behavior is reminiscent to what is found in films prepared by dip-coating, since the physical-chemical phenomena involved in the BAMS are very similar. ${ }^{[53,54]}$ The low coating speed region, where thicker films are obtained, corresponds to the capillary regime of the deposition, and it is governed by the evaporation rate. The viscous drag regime is found at the highest coating speeds (i.e., above $10 \mathrm{~mm} / \mathrm{s}$ ). This regime is usually related to Landau-Levich model. ${ }^{[55,56]} \mathrm{An}$ intermediate regime, described by both intermixed regimes is identified. ${ }^{[54]}$ This regime provides ultra-thin films that, in this case, are additionally smoother and with larger crystalline domains. On the contrary, the fast deposition speed in the viscous drag regime does not allow enough time for the crystallization resulting in smaller domain sizes.

In Figure 10 and Table S1, the values of mobility and SS versus the coating speed are depicted, while a representative transfer curve and output for each coating speed is shown in Figure S6 and Figure S7, respectively. The $V_{T H}$ and the on-off ratio do not show a clear pronounced tendency with the coating speed (Figure S8, Figure S9 and Table S1). Undoubtedly, the best device performance is obtained in the intermediate regime, achieving the maximum mobility of around $0.25 \mathrm{~cm}^{2} \mathrm{~V}^{-1} \mathrm{~s}^{-1}$ at $7.5 \mathrm{~mm} / \mathrm{s}(\gamma$-phase). This is attributed to the larger crystallites existing in these films. The mobility of the devices prepared at $1 \mathrm{~mm} / \mathrm{s}$ that correspond to the $\alpha$-phase of DB-TTF is of the order of $0.05 \mathrm{~cm}^{2} \mathrm{~V}^{-1} \mathrm{~s}^{-1}$, that is, five times less that the $\gamma$ polymorph. However, in solution-prepared $\alpha$-phase single-crystals a mobility of up to $1.0 \mathrm{~cm}^{2} \mathrm{~V}^{-1} \mathrm{~s}^{-1}$ was previously reported. ${ }^{[33]}$ Thus, we believe that the smaller crystalline 
domain size in the $\alpha$-phase thin films combined with the fact that the films are thicker might be detrimental for achieving the optimal device mobility. Regarding the SS parameter, the minimum values are obtained for coating speeds between 3 and $10 \mathrm{~mm} / \mathrm{s}$, since the wellordered films lead to a better OSC/dielectric interface.

\section{Semiconductor Molecule - Binder Polymer Ratio}

The influence of OSC:binder polymer ratio on the OFET performance was explored in thin films of DB-TTF/PS prepared by BAMS from $2.5 \%$ wt. solutions using a substrate temperature of $105^{\circ} \mathrm{C}$ and coating speed of $7.5 \mathrm{~mm} / \mathrm{s}$. For comparison, films of only DB-TTF were also prepared in the same conditions.

The optical microscope images show that the ratio DB-TTF:PS have a major impact on the thin films morphology (Figure 11). The thin films deposited from blends with more than $50 \%$ wt. of DB-TTF content show highly oriented crystals along the casting direction. On the other hand, the thin-films deposited from 1:1 blends or blends containing less than $50 \%$ wt. of DBTTF are more homogeneous with isotropic plate-like crystalline domains. XRD analysis demonstrate that the crystals from the latter films belong to the $\gamma$ polymorph, whereas when DB-TTF is the main component, films with a mixture of crystals from the $\alpha$ and $\gamma$ polymorphs are formed (Figure 12). We believe that this is probably caused by the different thermodynamics and kinetics processes involved during the vertical phase separation and crystallization. Further, it can also be hypothesized that at higher DB-TTF concentrations, molecular pre-aggregations in the solution might favor the growth of the thermodynamic polymorph. 
Representative transfer and output characteristics varying the OSC:binder polymer ratio are shown in Figure S10 and Figure S11, respectively. Cleary, the OSC formulation affects the device mobility and $V_{T H}$ (Figure 13). The phase mixture impacts on the device performance by reducing the charge transport. Thus, the best mobility values are achieved in the samples with only $\gamma$-phase, i.e. DB-TTF/PS ratio $1: 3$ and 1:2. Additionally, the morphological anisotropy observed in the films with more than 50 \% wt. of DB-TTF is also elucidated when measuring their electrical properties. In such devices a higher mobility is found when the coating direction is parallel to the channel length compared to when is perpendicular to it. This anisotropy is absent in devices with a lower DB-TTF content. It should be noticed that the films with high DB-TTF percentages are doped (i.e., $V_{T H}>>0$, high off current) and, hence the extraction of the mobility in such devices might be misleading. Films with a ratio of DB-TTF/PS 4:1 and with only DB-TTF were not considered to work as transistors because the on-off ratio was only about 10 (Figure S12). This enhanced doping could possibly be caused by the lower amount of PS that prevents an efficient encapsulation of the OSC. ${ }^{[30,40]}$ Importantly, to our knowledge this is the first time that it has been demonstrated that the ratio OSC:binder polymer has not only an influence on the thin films morphology and crystal size domains, but it can also determine the OSC polymorph or the polymorphism purity.

Finally, the transfer and output characteristics of the optimized device (substrate temperature of $105{ }^{\circ} \mathrm{C}$, coating speed of $7.5 \mathrm{~mm} / \mathrm{s}$ and OSC:binder polymer ratio 1:2) is shown in Figure 14. The devices exhibit ideal electrical characteristics with high on/off ratio, low subthreshold swing and $V_{T H}$ close to zero, showing low hysteresis in the output characteristic.

\section{Conclusion}

In conclusion, we reported that in solution sheared thin films formed from an OSC and an insulting polymer the substrate temperature and coating speed strongly affect the thin film morphology and polymorphism. In this way, depending on the experimental conditions the 
kinetic polymorph of DB-TTF or the thermodynamic one can be formed. Importantly, the latter has only been previously found in bulk single crystals. The best device performance was realized in an intermediate deposition regime between capillary and viscous drag regimes, where thinner and smother films with larger crystalline domains were formed. Further, we also demonstrated that the OSC:binder polymer ratio can also be crucial to prepare thin films from a pure polymorph. Substantial efforts are currently being devoted to the development of a plethora of solution processing techniques to deposit OSC thin films compatible with rollto-roll processes. However, for translating such techniques to real applications and achieve high device-to-device reproducibility, it is paramount to gain a full control on the thin film morphology and, especially, on polymorphism. Finally it should be emphasized that the control of polymorphism is not only pivotal in OFETs but also in all new emerging molecular-based electronic devices.

\section{Experimental Section}

Solution Blend Preparation: DB-TTF (purity 97 \%) and PS $3000 \mathrm{~g} / \mathrm{mol}$ were purchased from Sigma-Aldrich and used without further modifications. DB-TTF and PS were dissolved in cholorobenzene (2.5 wt \%). Previous to deposit, the blend solution is preheated at substrate temperature.

Materials and Device Fabrication: Source and drain electrodes were defined as interdigitated fingers by photolithography and a $\mathrm{Cr}(5 \mathrm{~nm})$ and $\mathrm{Au}(35 \mathrm{~nm})$ layer was deposited by thermal evaporation. The devices were fabricated on heavily n-doped Si wafer (Si-Mat) with $200 \mathrm{~nm}$ thick layer of SiOx. Before the deposition of the blend solutions, the substrates were cleaned in ultrasonic bath with acetone and isopropanol, and then dried under nitrogen flow. Finally, the active layer was deposited on the substrates by BAMS technique, using home-designed equipment. Note that all fabrication process was carried out under ambient conditions and no post-thermal treatments were required. 
Thin film Characterization: Optical microscope images were taken using the Olympus BX51 equipped with polarizer and analyser. The domain sizes were calculated using the ImageJ software. X-ray diffraction measurements were carried out with a PANalytical X'Pert Pro MRD (Materials Research Diffractometer) diffractometer. The used Cu K-alpha radiation was $1.54187 \AA$ Å. Surface topography and film thickness were examined by a 5500LS SPM system from Agilent Technologies and subsequent data analysis was performed by using Gwyddion 2.41 software.

Device Characterization: Transistor measurements were carried out in bottom-gate, bottomcontact geometry. The transfer and output characteristics were measured with the Agilent B1500A semiconductor device analyzer at ambient conditions. For all transfer measurement the $V_{D S}$ is $-40 \mathrm{~V}$. The devices were characterized extracting the field-effect mobility in saturation regime, threshold voltage $\left(V_{T H}\right)$, on-off ratio and sub-threshold swing (SS) parameters. $\mu$ and SS were calculated using the following equations (Equation 1 and 2):

$\mu^{s a t}=\left(\frac{\partial \sqrt{I_{D S} S}}{\partial V_{G}}\right)^{2} \frac{2 L}{W} \cdot \frac{1}{C}$

$S S=\frac{\partial V_{G}}{\partial\left(\log I_{D S}\right)}$

where $W$ and $L$ are the width and length of the channel, respectively, and $C$ is the insulator capacitance per unit area. The respectively values are $W=10 \mathrm{~cm} ; L=25,50,75$ and $100 \mu \mathrm{m}$; and $\mathrm{C}=17.26 \mathrm{nF}$. A minimum of 42 devices were measured under each condition.

\section{Acknowledgements}

This work was mainly funded by the ERC StG 2012-306826 e-GAMES and ERC PoC 2014640120 LAB-TECH projects. The authors also thank the Networking Research Center on Bioengineering, Biomaterials, and Nanomedicine (CIBER-BBN), the DGI (Spain) project BE-WELL CTQ 2013-40480-R and FANCY CTQ2016-80030-R, the Generalitat de Catalunya (2014-SGR-17) and the Spanish Ministry of Economy and Competitiveness, 
through the "Severo Ochoa” Programme for Centers of Excellence in R\&D (SEV-20150496). F.L. gratefully acknowledges the “Juan de la Cierva” programme.

Received: ((will be filled in by the editorial staff))

Revised: ((will be filled in by the editorial staff)) Published online: ((will be filled in by the editorial staff))

\section{References}

[1] Y. Diao, B. C.-K. Tee, G. Giri, J. Xu, D. H. Kim, H. A. Becerril, R. M. Stoltenberg, T. H. Lee, G. Xue, S. C. B. Mannsfeld, Z. Bao, Nat. Mater. 2013, 12, 665.

[2] S. Park, G. Giri, L. Shaw, G. Pitner, J. Ha, J. H. Koo, X. Gu, J. Park, T. H. Lee, J. H. Nam, Y. Hong, Z. Bao, Proc. Natl. Acad. Sci. U. S. A. 2015, 112, 5561.

[3] C. Di, Y. Liu, G. Yu, D. Zhu, D. Z. C. Di, Y. Liu, G. Yu, C. Di, Y. Liu, G. Yu, D. Zhu, Acc. Chem. Res. 2009, 42, 1573.

[4] H. Dong, L. Jiang, W. Hu, Phys. Chem. Chem. Phys. 2012, 14, 14165.

[5] J. W. Ward, R. Li, A. Obaid, M. M. Payne, D. M. Smilgies, J. E. Anthony, A. Amassian, O. D. Jurchescu, Adv. Funct. Mater. 2014, 24, 5052.

[6] V. Coropceanu, J. Cornil, D. A. da Silva Filho, Y. Olivier, R. Silbey, J.-L. Brédas, Chem. Rev. 2007, 107, 926.

[7] M. Mas-Torrent, C. Rovira, Chem. Rev. 2011, 111, 4833.

[8] R. Pfattner, M. Mas-Torrent, I. Bilotti, A. Brillante, S. Milita, F. Liscio, F. Biscarini, T. Marszalek, J. Ulanski, A. Nosal, M. Gazicki-Lipman, M. Leufgen, G. Schmidt, W. M. Laurens, V. Laukhin, J. Veciana, C. Rovira, L. W. Molenkamp, V. Laukhin, J. Veciana, C. Rovira, Adv. Mater. 2010, 22, 4198.

[9] H. Jiang, X. Yang, Z. Cui, Y. Liu, H. Li, W. Hu, Y. Liu, D. Zhu, Appl. Phys. Lett. 2007, 91, 2005.

[10] O. D. Jurchescu, D. A. Mourey, S. Subramanian, S. R. Parkin, B. M. Vogel, J. E. Anthony, T. N. Jackson, D. J. Gundlach, Phys. Rev. B 2009, 80, 085201.

[11] T. He, M. Stolte, C. Burschka, N. H. Hansen, T. Musiol, D. Kälblein, J. Pflaum, X. Tao, J. Brill, F. Würthner, Nat. Commun. 2015, 6, 5954.

[12] A. K. Tripathi, J. Pflaum, Appl. Phys. Lett. 2006, 89, 14.

[13] L. A. Stevens, K. P. Goetz, A. Fonari, Y. Shu, R. M. Williamson, J. L. Brédas, V. Coropceanu, O. D. Jurchescu, G. E. Collis, Chem. Mater. 2015, 27, 112.

[14] P. He, Z. Tu, G. Zhao, Y. Zhen, H. Geng, Y. Yi, Z. Wang, H. Zhang, C. Xu, J. Liu, X. Lu, X. Fu, Q. Zhao, X. Zhang, D. Ji, L. Jiang, H. Dong, W. Hu, Adv. Mater. 2015, 27, 
825.

[15] E. Gann, X. Gao, C. A. Di, C. R. McNeill, Adv. Funct. Mater. 2014, 24, 7211.

[16] G. Schweicher, N. Paquay, C. Amato, R. Resel, M. Koini, S. Talvy, V. Lemaur, J. Cornil, Y. Geerts, G. Gbabode, Cryst. Growth Des. 2011, 11, 3663.

[17] J. Wan, Y. Li, J. G. Ulbrandt, D. M. Smilgies, J. Hollin, A. C. Whalley, R. L. Headrick, APL Mater. 2016, 4.

[18] Y. Li, J. Wan, D.-M. Smilgies, N. Bouffard, R. Sun, R. L. Headrick, Sci. Rep. 2016, 6, 32620.

[19] D. H. Kim, H. S. Lee, H. Yang, L. Yang, K. Cho, Adv. Funct. Mater. 2008, 18, 1363.

[20] J. Chen, M. Shao, K. Xiao, A. J. Rondinone, Y.-L. Loo, P. R. C. Kent, B. G. Sumpter, D. Li, J. K. Keum, P. J. Diemer, J. E. Anthony, O. D. Jurchescu, J. Huang, Nanoscale 2014, 6, 449.

[21] A. M. Hiszpanski, R. M. Baur, B. Kim, N. J. Tremblay, C. Nuckolls, A. R. Woll, Y. L. Loo, J. Am. Chem. Soc. 2014, 136, 15749.

[22] G. E. Purdum, N. Yao, A. Woll, T. Gessner, R. T. Weitz, Y. L. Loo, Adv. Funct. Mater. 2016, 26, 2357.

[23] H. L. Cheng, Y. S. Mai, W. Y. Chou, L. R. Chang, X. W. Liang, Adv. Funct. Mater. 2007, 17, 3639.

[24] S. C. B. Mannsfeld, A. Virkar, C. Reese, M. F. Toney, Z. Bao, Adv. Mater. 2009, 21, 2294.

[25] P. S. Jo, D. T. Duong, J. Park, R. Sinclair, A. Salleo, Chem. Mater. 2015, 27, 3979.

[26] G. Giri, E. Verploegen, S. C. B. Mannsfeld, S. Atahan-Evrenk, D. H. Kim, S. Y. Lee, H. a. Becerril, A. Aspuru-Guzik, M. F. Toney, Z. Bao, Nature 2011, 480, 504.

[27] B. Wedl, R. Resel, G. Leising, B. Kunert, I. Salzmann, M. Oehzelt, N. Koch, A. Vollmer, S. Duhm, O. Werzer, G. Gbabode, M. Sferrazza, Y. Geerts, RSC Adv. 2012, 2, 4404.

[28] Y. Diao, K. M. Lenn, W. Lee, M. A. Blood-forsythe, J. Xu, Y. Mao, Y. Kim, J. A. Reinspach, S. Park, G. Xue, P. Clancy, J. Am. Chem. Soc. 2014, 136, 17046.

[29] Y. Xu, C. Liu, D. Khim, Y.-Y. Noh, Phys. Chem. Chem. Phys. 2015, 17, 26553.

[30] F. G. Del Pozo, S. Fabiano, R. Pfattner, S. Georgakopoulos, S. Galindo, X. Liu, S. Braun, M. Fahlman, J. Veciana, C. Rovira, X. Crispin, M. Berggren, M. Mas-Torrent, Adv. Funct. Mater. 2016, 26, 2379.

[31] A. Brillante, I. Bilotti, R. G. Della Valle, E. Venuti, M. Mas-Torrent, C. Rovira, Y. Yamashita, Chem. Phys. Lett. 2012, 523, 74.

[32] A. Brillante, I. Bilotti, R. G. Della Valle, E. Venuti, S. Milita, C. Dionigi, F. Borgatti, 
A. N. Lazar, F. Biscarini, M. Mas-Torrent, N. S. Oxtoby, N. Crivillers, J. Veciana, C. Rovira, M. Leufgen, G. Schmidt, L. W. Molenkamp, CrystEngComm 2008, 10, 1899.

[33] M. Mas-Torrent, P. Hadley, S. T. Bromley, N. Crivillers, J. Veciana, C. Rovira, Appl. Phys. Lett. 2005, 86, 12110.

[34] M. Leufgen, O. Rost, C. Gould, G. Schmidt, J. Geurts, L. W. Molenkamp, N. S. Oxtoby, M. Mas-Torrent, N. Crivillers, J. Veciana, C. Rovira, Org. Electron. 2008, 9, 1101.

[35] N. Naraso, J.-I. Nishida, S. Ando, J. Yamaguchi, K. Itaka, H. Koinuma, H. Tada, S. Tokito, Y. Yamashita, J. Am. Chem. Soc. 2005, 127, 10142.

[36] B. Noda, H. Wada, K. Shibata, T. Yoshino, M. Katsuhara, I. Aoyagi, T. Mori, T. Taguchi, T. Kambayashi, K. Ishikawa, H. Takezoe, Nanotechnology 2007, 18, 424009.

[37] T. Yamada, T. Hasegawa, M. Hiraoka, H. Matsui, Y. Tokura, G. Saito, Appl. Phys. Lett. 2008, 92, 233306.

[38] J. Nagakubo, M. Ashizawa, T. Kawamoto, A. Tanioka, T. Mori, Phys. Chem. Chem. Phys. 2011, 13, 14370.

[39] S. Georgakopoulos, F. G. del Pozo, M. Mas-Torrent, J. Mater. Chem. C 2015, 3, 12199.

[40] F. Leonardi, S. Casalini, Q. Zhang, S. Galindo, D. Gutiérrez, M. Mas-torrent, Adv. Mater. 2016, 28, 10311.

[41] I. Temiño, F. G. Del Pozo, M. R. Ajayakumar, S. Galindo, J. Puigdollers, M. MasTorrent, Adv. Mater. Technol. 2016, 1, 1600090.

[42] J. G. Laquindanum, H. E. Katz, A. J. Lovinger, J. Am. Chem. Soc. 1998, 120, 664.

[43] G. Horowitz, M. E. Hajlaoui, Synth. Met. 2001, 122, 185.

[44] M. Shtein, J. Mapel, J. B. Benziger, S. R. Forrest, Appl. Phys. Lett. 2002, 81, 268.

[45] J. A. Letizia, A. Facchetti, C. L. Stern, M. A. Ratner, T. J. Marks, J. Am. Chem. Soc. 2005, 127, 13476.

[46] J. Locklin, M. E. Roberts, S. C. B. Mannsfeld, Z. Bao, J. Macromol. Sci. Part C Polym. Rev. 2006, 46, 79.

[47] S. Scheinert, G. Paasch, M. Schrödner, H. K. Roth, S. Sensfuß, T. Doll, J. Appl. Phys. 2002, 92, 330.

[48] G. Giri, S. Park, M. Vosgueritchian, M. M. Shulaker, Z. Bao, Adv. Mater. 2014, 26, 487.

[49] M. R. Niazi, R. Li, E. Qiang Li, A. R. Kirmani, M. Abdelsamie, Q. Wang, W. Pan, M. M. Payne, J. E. Anthony, D.-M. Smilgies, S. T. Thoroddsen, E. P. Giannelis, A. Amassian, Nat. Commun. 2015, 6, 8598. 
[50] M. R. Niazi, R. Li, M. Abdelsamie, K. Zhao, D. H. Anjum, M. M. Payne, J. Anthony, D. M. Smilgies, A. Amassian, Adv. Funct. Mater. 2016, 26, 2371.

[51] G. Giri, D. M. DeLongchamp, J. Reinspach, D. a. Fischer, L. J. Richter, J. Xu, S. Benight, A. Ayzner, M. He, L. Fang, G. Xue, M. F. Toney, Z. Bao, Chem. Mater. 2015, 27, 2350.

[52] W. Ma, J. Reinspach, Y. Zhou, Y. Diao, T. McAfee, S. C. B. Mannsfeld, Z. Bao, H. Ade, Adv. Funct. Mater. 2015, 25, 3131.

[53] M. Faustini, M. Faustini, B. Louis, P. A. Albouy, M. Kuemmel, D. Grosso, J. Phys. Chem. C 2010, 114, 7637.

[54] D. Grosso, J. Mater. Chem. 2011, 21, 17033.

[55] L. Landau, B. Levich, Acta Physicochim. URSS 1942, 17, 42.

[56] H. N. Dixit, G. M. Homsy, J. Fluid Mech. 2013, 732, 5. 
<smiles>c1ccc2c(c1)SC(=C1Sc3ccccc3S1)S2</smiles><smiles>CC(CC(C)(C)C)C(C)(C)C</smiles>

Figure 1. Molecular structure of DB-TTF (left) and PS (right).

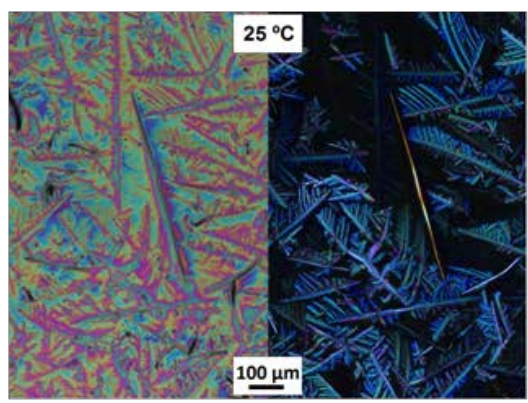

$80^{\circ} \mathrm{C}$

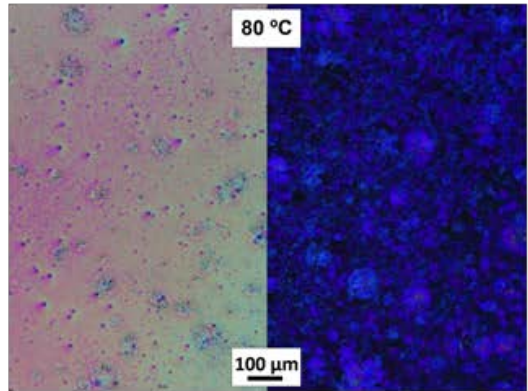

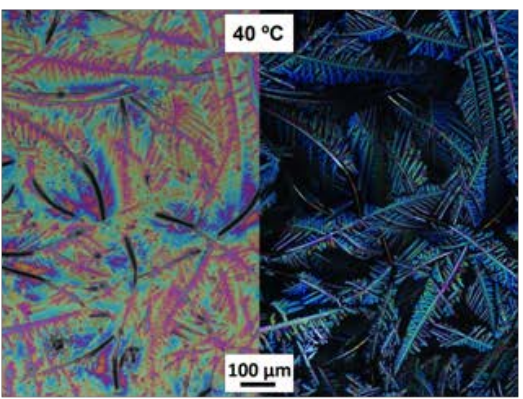

$105^{\circ} \mathrm{C}$

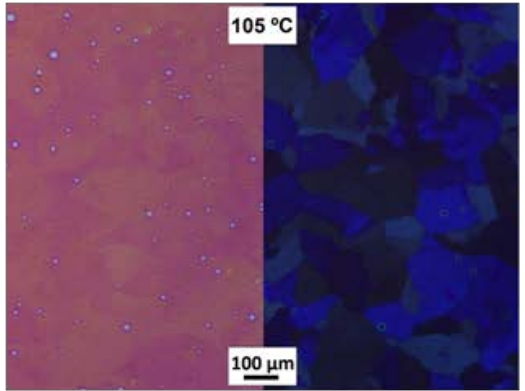

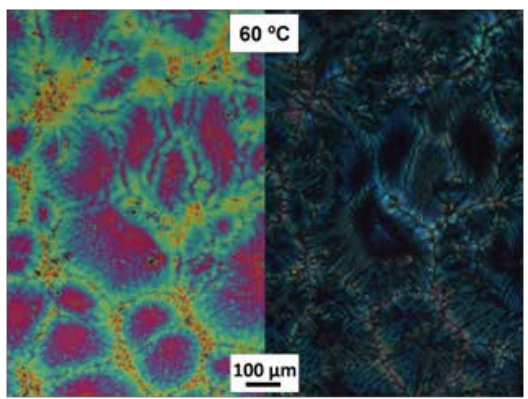

$120^{\circ} \mathrm{C}$

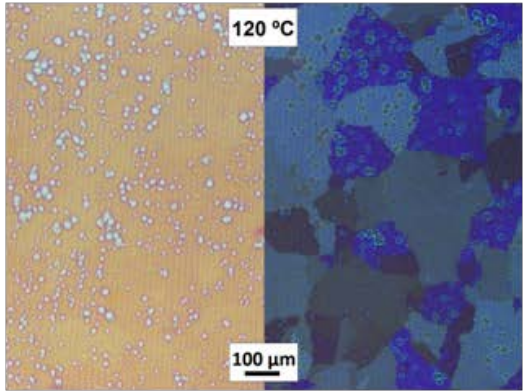

Figure 2. Optical microscopy images of DB-TTF/PS thin films deposited by BAMS technique at different substrate temperatures. For each temperature the non-polarized (left) and polarized (right) images are shown.

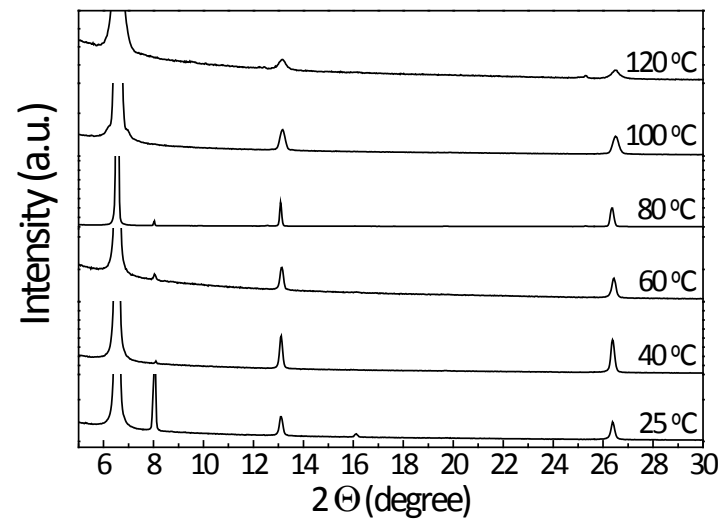

Figure 3. XRD diffractograms of DB-TTF/PS thin films deposited by BAMS technique at different substrate temperatures. 


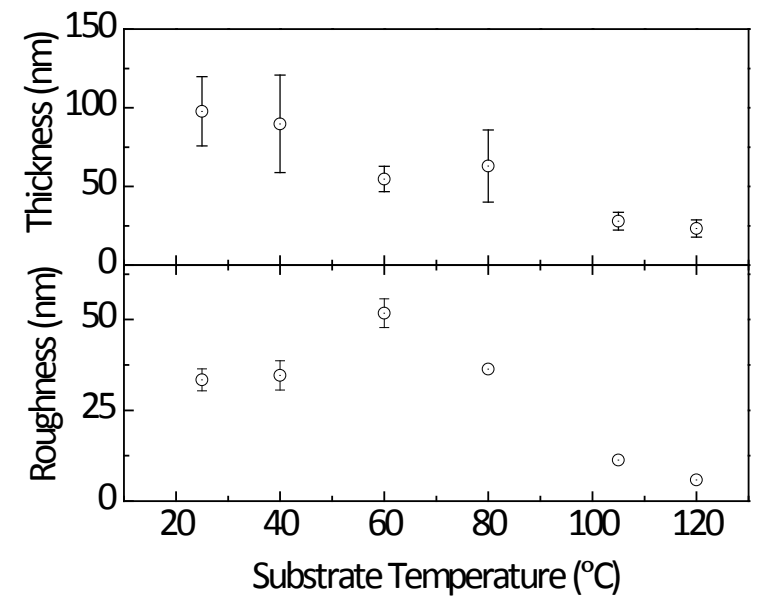

Figure 4. Mean values of thickness (top) and roughness (bottom) of DB-TTF/PS films deposited by BAMS at different substrate temperatures.

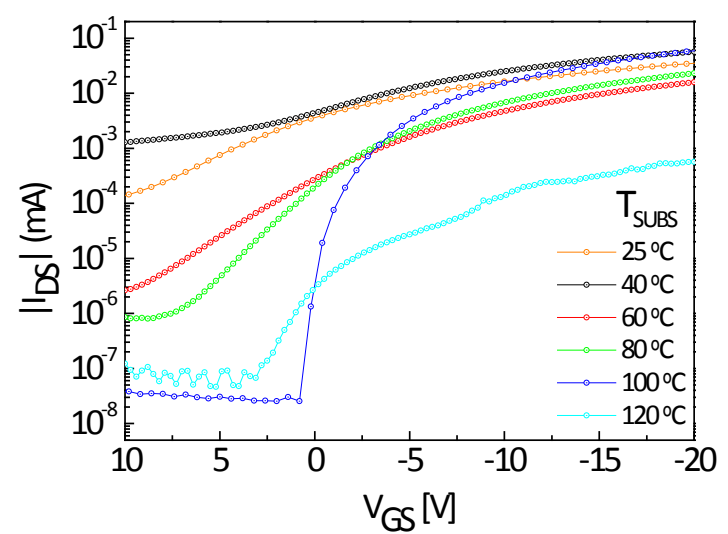

Figure 5. Transfer characteristics of the OFETs based on DB-TTF/PS at different substrate temperatures.

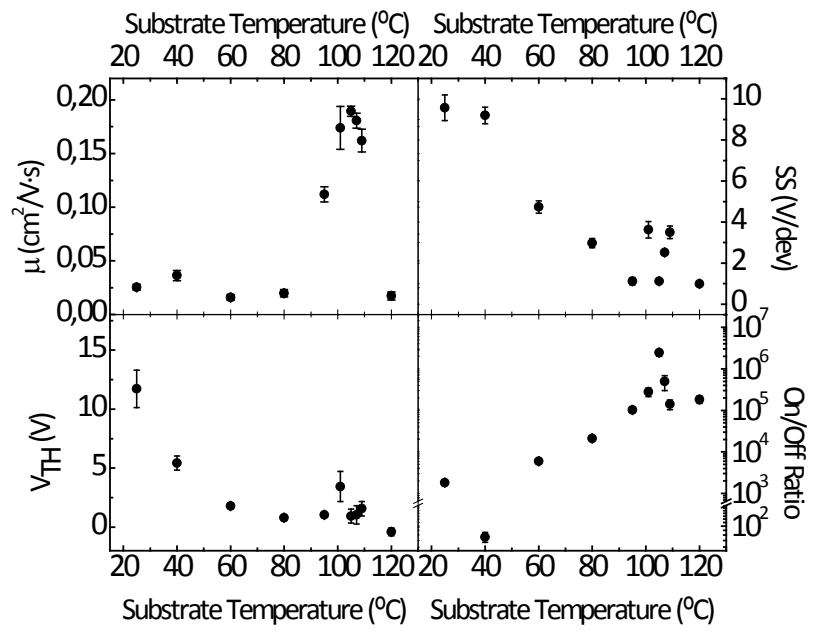

Figure 6. Mean values with standard deviation of the main OFET parameters (i.e., $\mu, V_{T H}$, sub-threshold swing (SS), and on/off ratio) where the active DB-TTF/PS layer has been deposited at different substrate temperatures. 

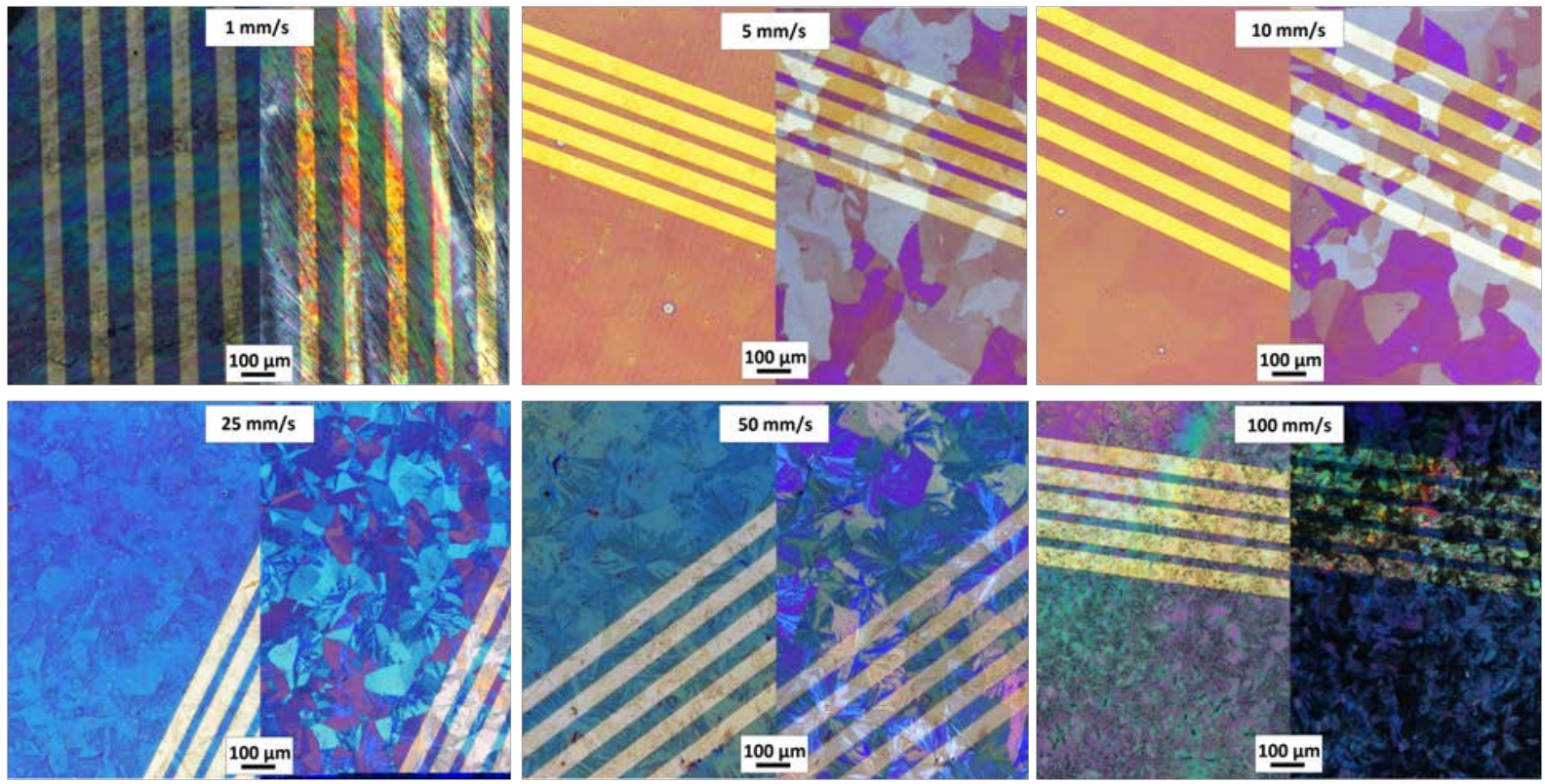

Figure 7. Optical microscopy images of DB-TTF/PS 1:2 thin films deposited by BAMS technique at $105^{\circ} \mathrm{C}$ and at different coating speeds. For each temperature the non-polarized (left) and polarized (right) images are depicted.

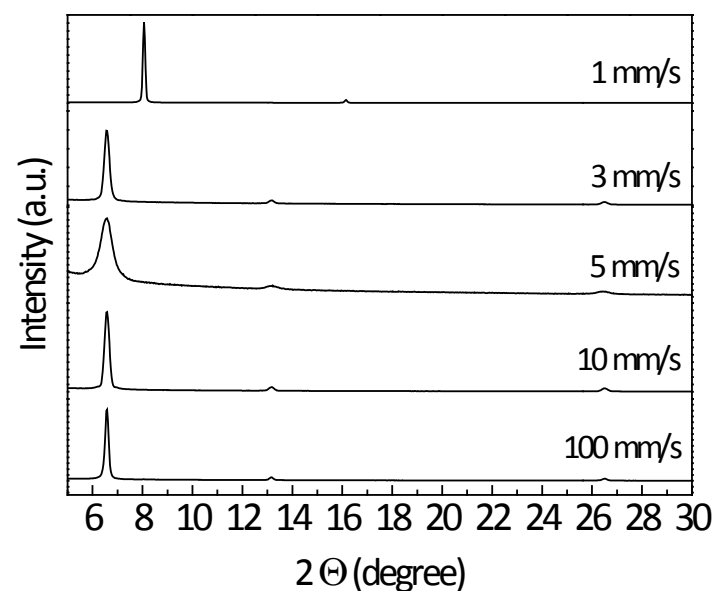

Figure 8. XRD diffractograms of DB-TTF/PS 1:2 thin films deposited by BAMS at $105^{\circ} \mathrm{C}$ and at different coating speeds. 


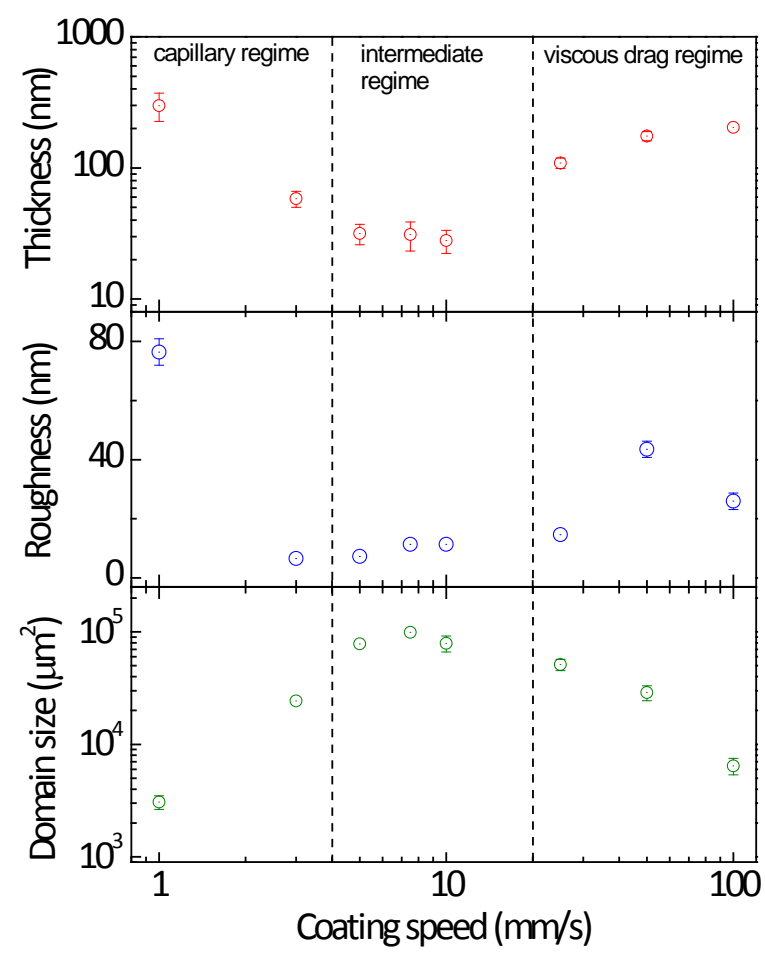

Figure 9. Thickness (top), roughness (middle) and domain size (bottom) of DB-TTF/PS 1:2 thin films deposited by BAMS at $105^{\circ} \mathrm{C}$ and at different coating speeds.

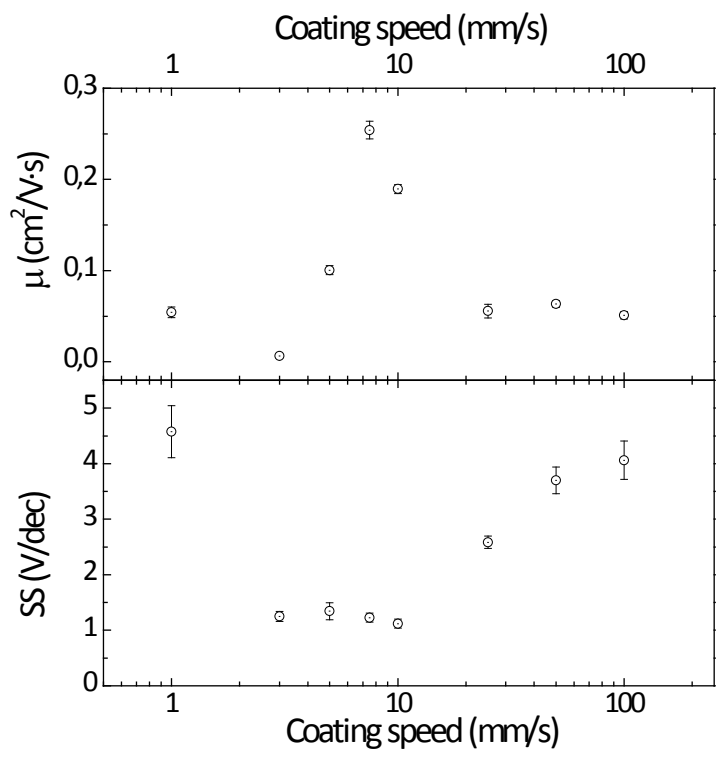

Figure 10. Mean mobility and $S S$ values with standard deviation of DB-TTF/PS 1:2 OFETs with active layer deposited at $105^{\circ} \mathrm{C}$ and at different coating speed. 

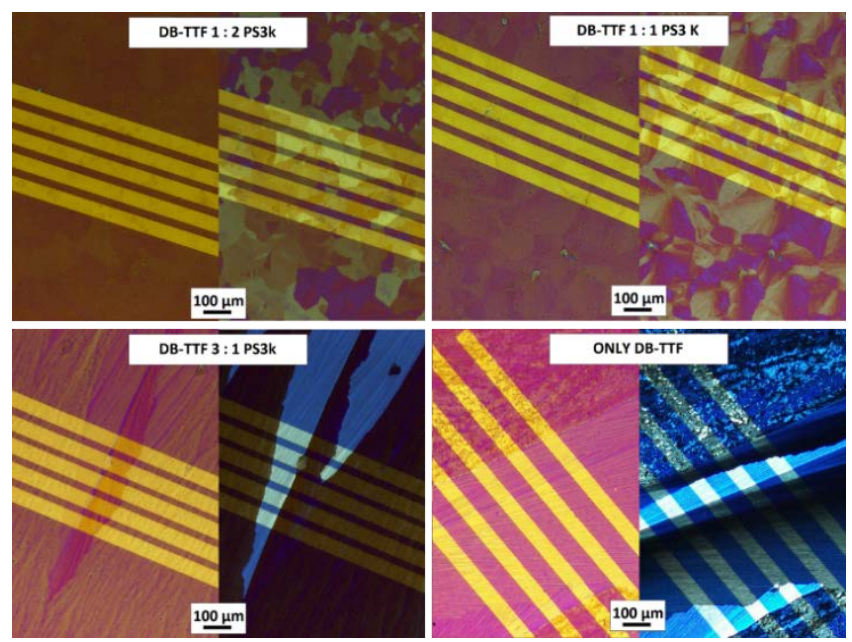

Figure 11. Optical microscopy images of DB-TTF/PS thin films with different OSC:binder polymer ratio deposited by BAMS at $105^{\circ} \mathrm{C}$ at $7.5 \mathrm{~mm} / \mathrm{s}$. For each formulation non-polarized (left) and polarized (right) images are depicted.

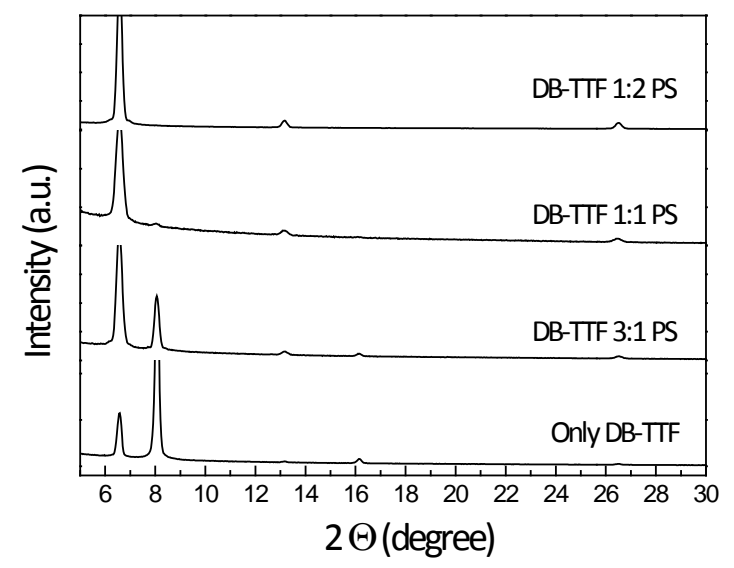

Figure 12. XRD diffractograms of DB-TTF/PS thin films with different OSC:binder polymer ratio deposited by BAMS technique at $105^{\circ} \mathrm{C}$ and $7.5 \mathrm{~mm} / \mathrm{s}$.

DB-TTF:PS

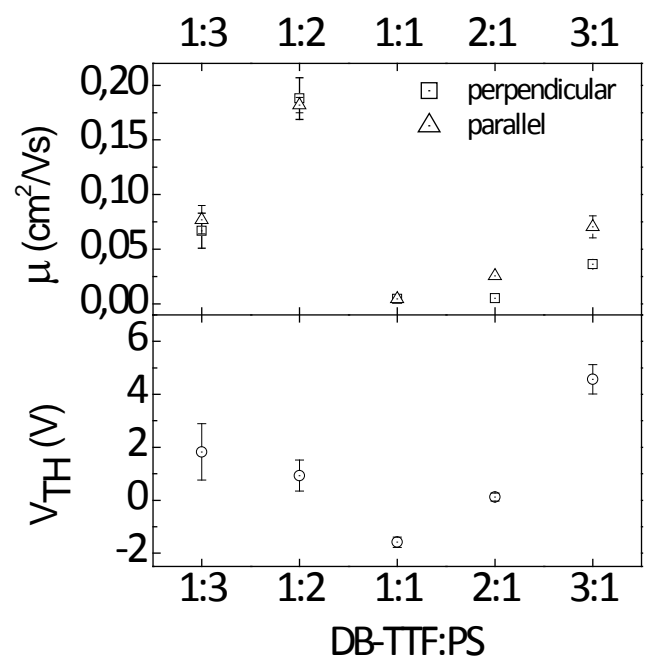

Figure 13. Mean mobility and $S S$ of DB-TTF/PS OFETs prepared at $105^{\circ} \mathrm{C}$ and $10 \mathrm{~mm} / \mathrm{s}$ with different OSC:binder polymer ratio. 

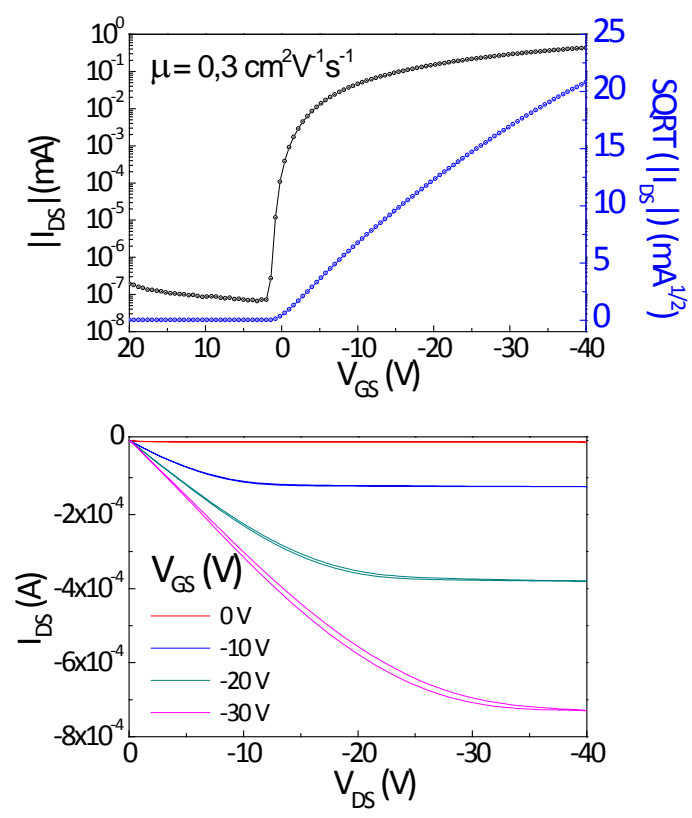

Figure 14. Output and transfer characteristic of the optimized device. 


\section{Supporting Information}

Control of polymorphism and morphology in solution sheared organic field-effect transistors

Sergi Galindo ${ }^{\ddagger}$, Adrián Tamayo ${ }^{\ddagger}$,Francesca Leonardi and Marta Mas-Torrent*

Table S1. Average of main OFET parameters measured and its standard deviation extracted from transfer characteristics for the fabricated devices. At least 42 devices have been prepared in each specific experimental conditions.

\begin{tabular}{cccccc}
$\begin{array}{c}\text { Substrate } \\
\text { Temperature } \\
\left({ }^{\circ} \mathbf{C}\right)\end{array}$ & $\begin{array}{c}\text { Coating } \\
\text { speed } \\
(\mathbf{m m} / \mathbf{s})\end{array}$ & $\boldsymbol{\mu}\left(\mathbf{c m}^{\mathbf{2}} \mathbf{V}^{-1} \mathbf{s}^{-1}\right)$ & $\boldsymbol{V}_{\text {TH }}(\mathbf{V})$ & SS $(\mathbf{V} / \mathbf{d e c})$ & on/off ratio \\
\hline 25 & 10 & $0.03 \pm 0.003$ & $11.7 \pm 1.6$ & $9.6 \pm 0.6$ & $(1.8 \pm 0.3) \cdot 10^{3}$ \\
40 & 10 & $0.04 \pm 0.005$ & $5.4 \pm 0.6$ & $9.2 \pm 0.4$ & $(7.0 \pm 1) \cdot 10^{1}$ \\
60 & 10 & $0.02 \pm 0.003$ & $1.8 \pm 0.3$ & $4.7 \pm 0.3$ & $(6.0 \pm 0.7) \cdot 10^{3}$ \\
80 & 10 & $0.02 \pm 0.003$ & $0.8 \pm 0.2$ & $3.0 \pm 0.2$ & $(2.1 \pm 0.3) \cdot 10^{4}$ \\
95 & 10 & $0.11 \pm 0.007$ & $1.0 \pm 0.1$ & $1.1 \pm 0.2$ & $(1.0 \pm 0.2) \cdot 10^{5}$ \\
100 & 10 & $0.17 \pm 0.020$ & $3.4 \pm 1.3$ & $3.6 \pm 0.4$ & $(2.8 \pm 0.6) \cdot 10^{5}$ \\
105 & 10 & $0.19 \pm 0.005$ & $0.9 \pm 0.6$ & $1.1 \pm 0.1$ & $(2.4 \pm 0.4) \cdot 10^{6}$ \\
110 & 10 & $0.16 \pm 0.011$ & $1.6 \pm 1.6$ & $3.5 \pm 0.3$ & $(1.4 \pm 0.4) \cdot 10^{5}$ \\
120 & 10 & $0.02 \pm 0.004$ & $-0.4 \pm 0.6$ & $1.0 \pm 0.1$ & $(4.0 \pm 4) \cdot 10^{4}$ \\
\hline 105 & 1 & $0.05 \pm 0.006$ & $1.6 \pm 1.0$ & $4.6 \pm 0.5$ & $(2.4 \pm 0.6) \cdot 10^{5}$ \\
105 & 3 & $0.01 \pm 0.001$ & $2.0 \pm 0.3$ & $1.3 \pm 0.1$ & $(2.5 \pm 0.4) \cdot 10^{4}$ \\
105 & 5 & $0.10 \pm 0.005$ & $1.6 \pm 0.4$ & $1.3 \pm 0.2$ & $(3.1 \pm 0.5) \cdot 10^{5}$ \\
105 & 7.5 & $0.25 \pm 0.010$ & $1.3 \pm 0.1$ & $1.2 \pm 0.1$ & $(3.5 \pm 0.4) \cdot 10^{5}$ \\
105 & 10 & $0.19 \pm 0.005$ & $0.9 \pm 0.6$ & $1.1 \pm 0.1$ & $(2.4 \pm 0.4) \cdot 10^{6}$ \\
105 & 25 & $0.06 \pm 0.008$ & $2.8 \pm 0.2$ & $2.6 \pm 0.1$ & $(5.0 \pm 1) \cdot 10^{5}$ \\
105 & 50 & $0.06 \pm 0.004$ & $4.0 \pm 0.3$ & $3.7 \pm 0.2$ & $(4.0 \pm 0.6) \cdot 10^{4}$
\end{tabular}



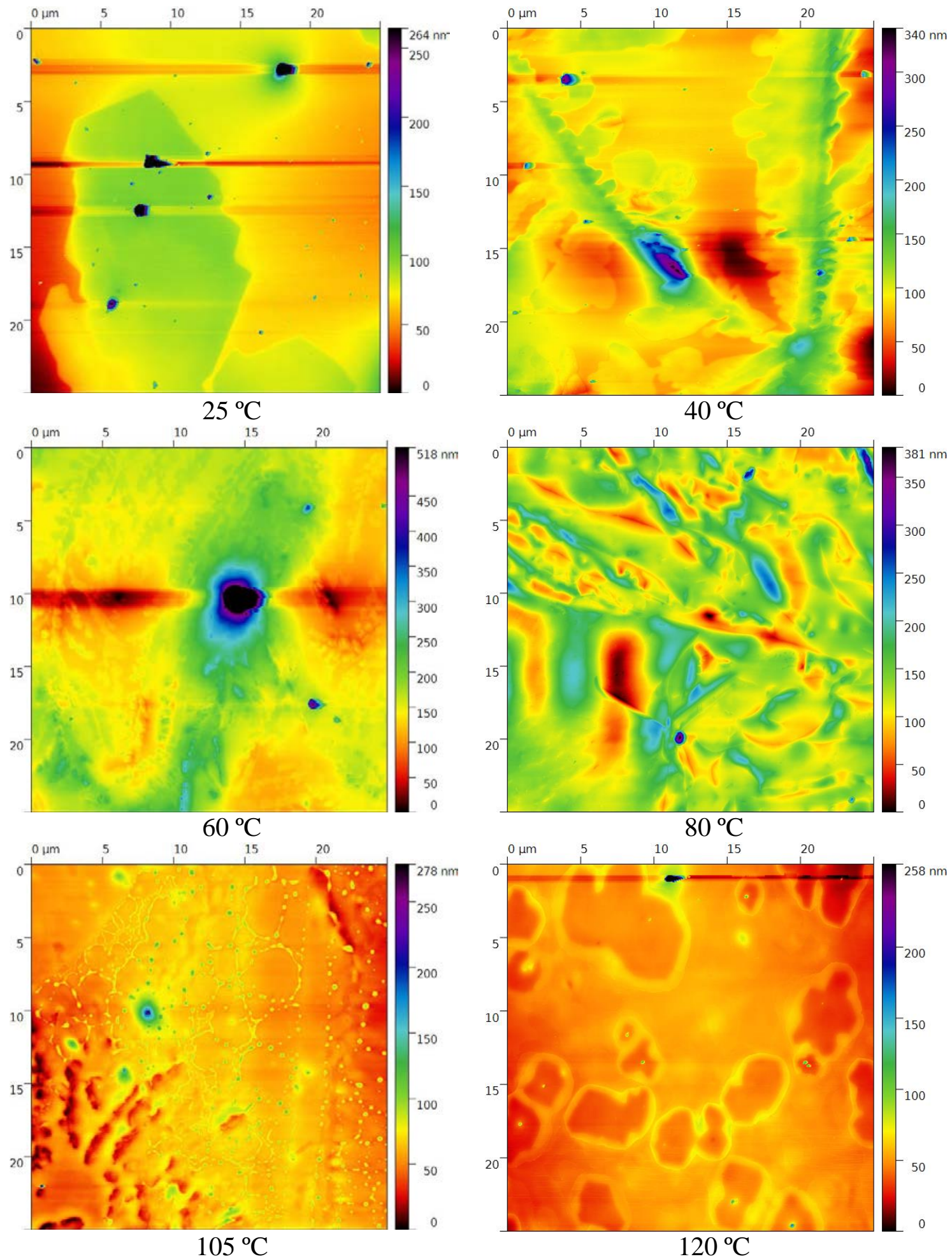

Figure S1. Topographical AFM images of DB-TTF/PS thin films deposited at different substrate temperature. 


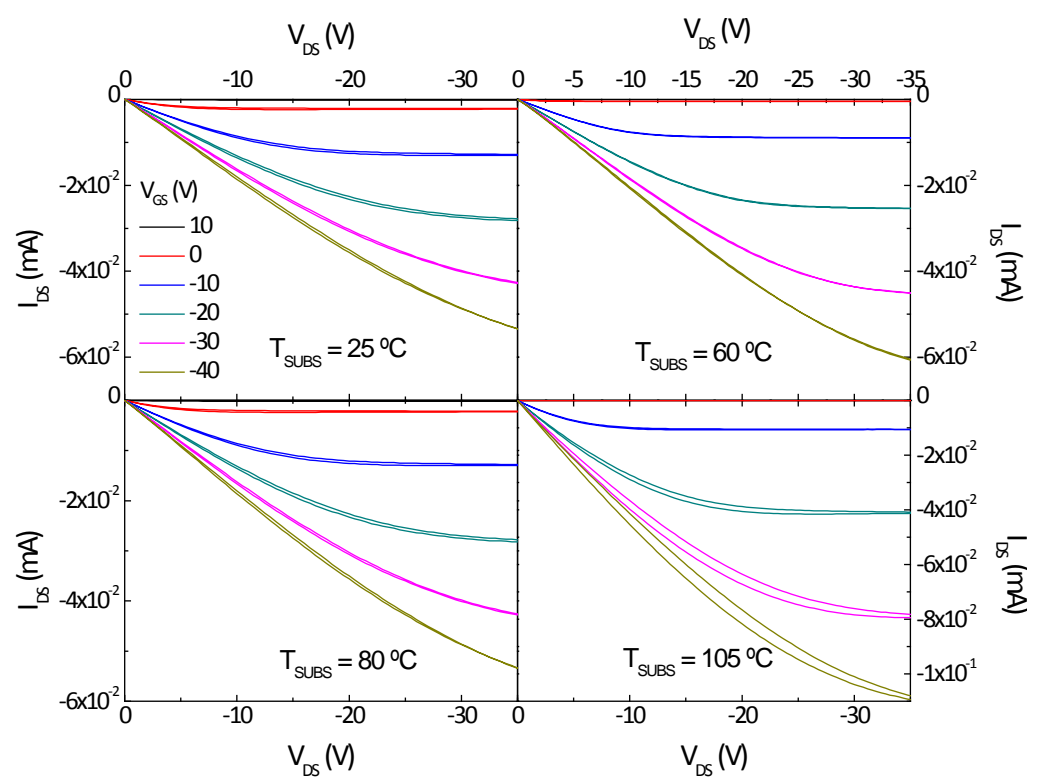

Figure S2. Output characteristics of OFETs based on DB-TTF/PS deposited at different substrate temperature.

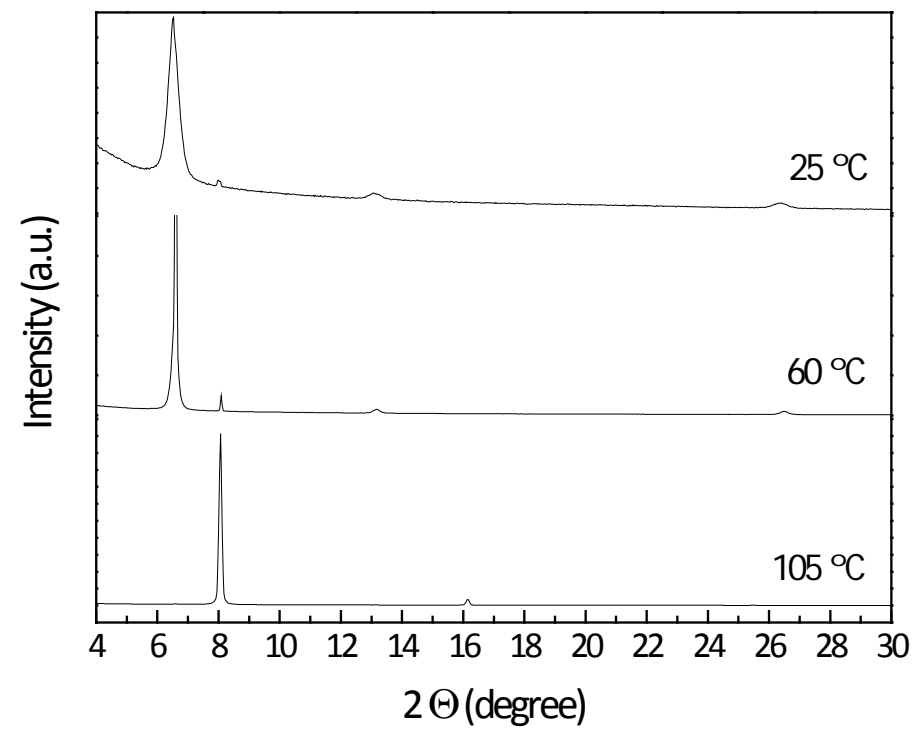

Figure S3. XRD of films deposited at coating speed of $1 \mathrm{~mm} / \mathrm{s}$ at different substrate temperature. 

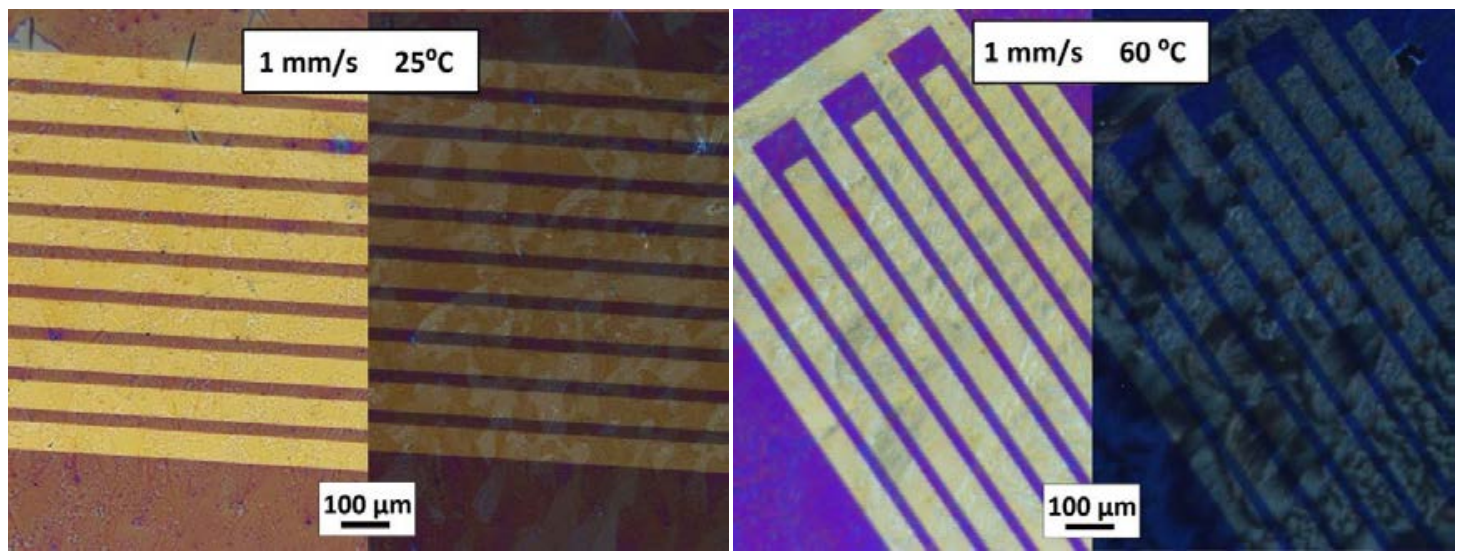

Figure S4. Optical microscope images of DB-TTF/PS films deposited at $1 \mathrm{~mm} / \mathrm{s}$ at substrate temperature of 25 and $60{ }^{\circ} \mathrm{C}$. 

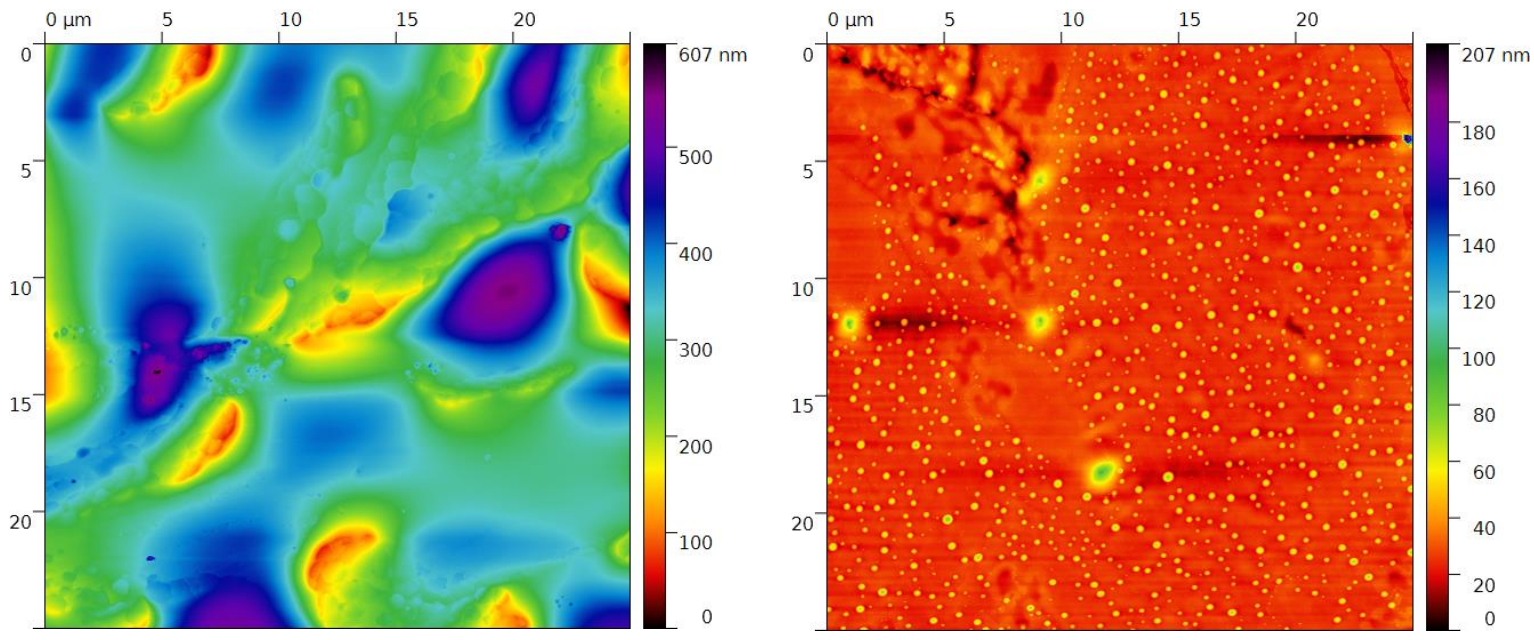

$1 \mathrm{~mm} / \mathrm{s}$
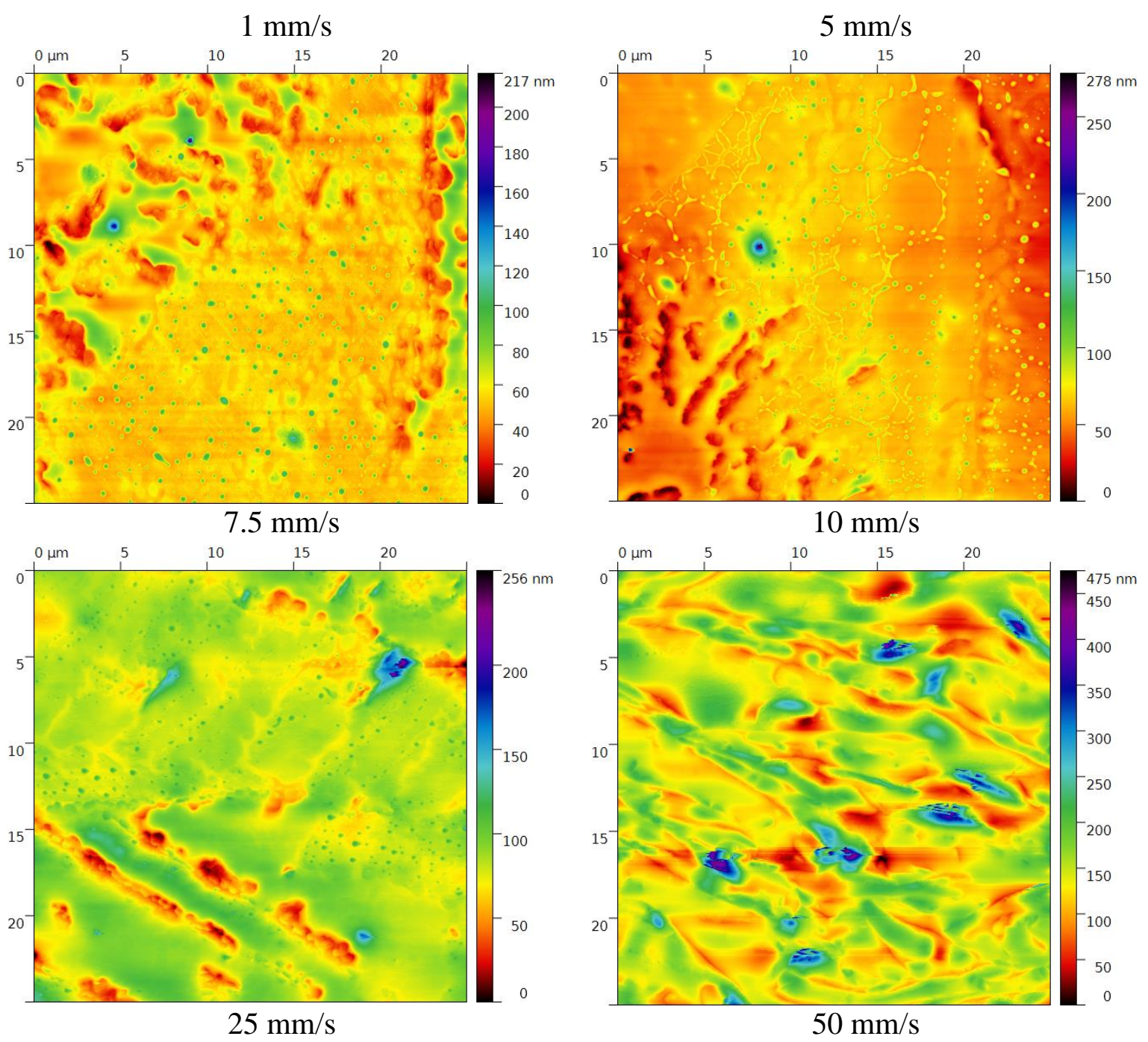


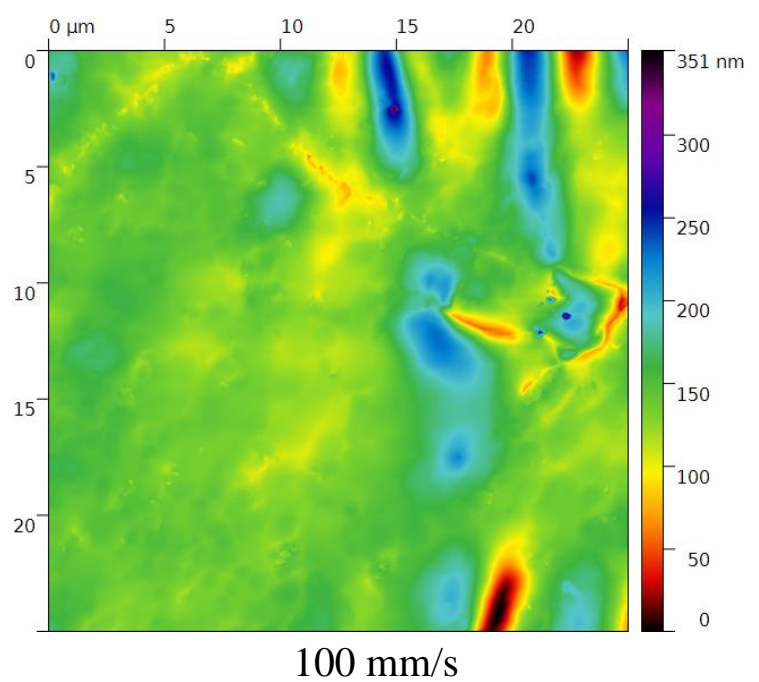

Figure S5. Topographical AFM images of DB-TTF/PS thin films deposited at different coating speed.

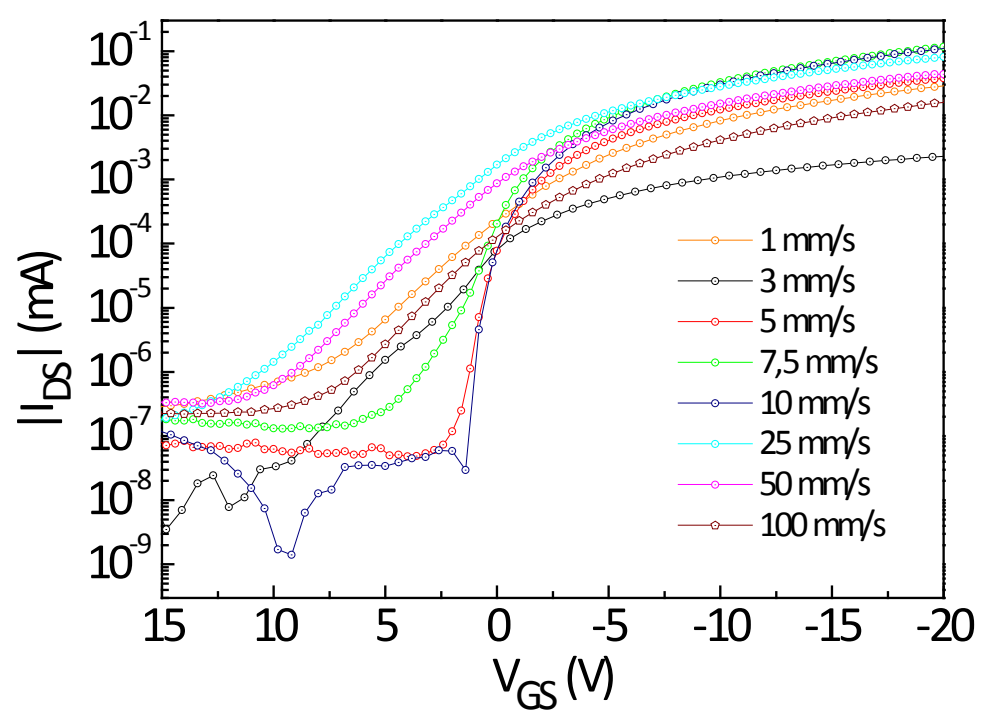

Figure S6. Transfer characteristics of OFETs based on DB-TTF/PS deposited at different coating speed. 


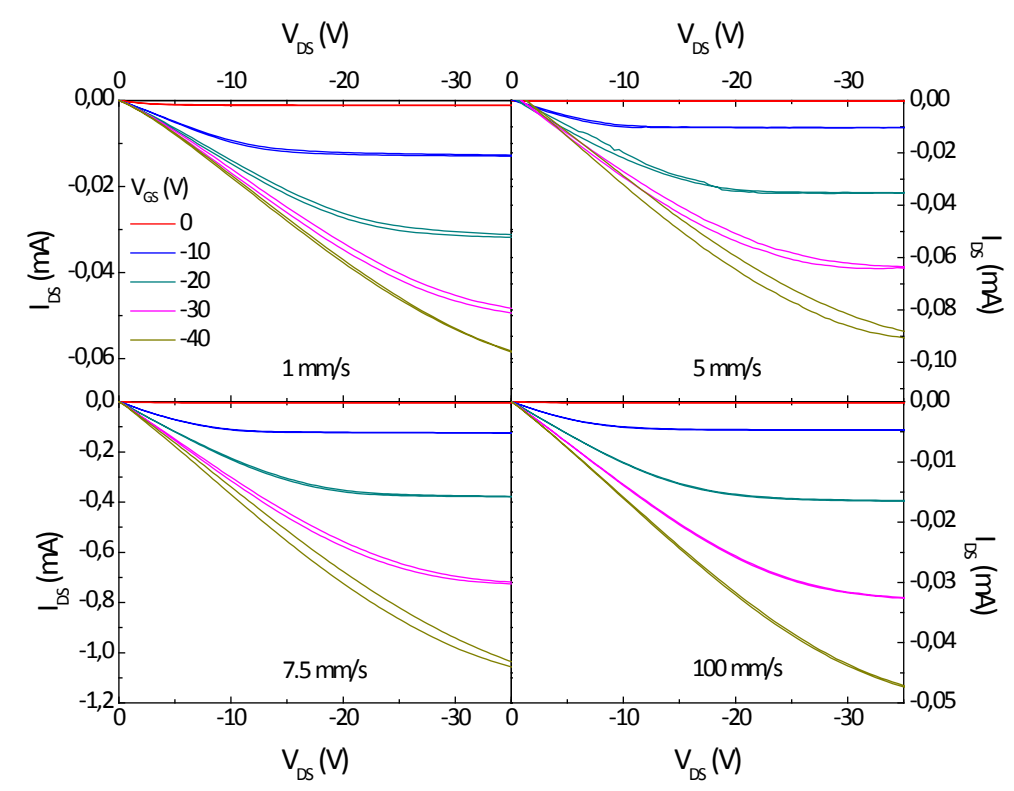

Figure S7. Output characteristic of OFETs based on DB-TTF/PS deposited at different coating speed.

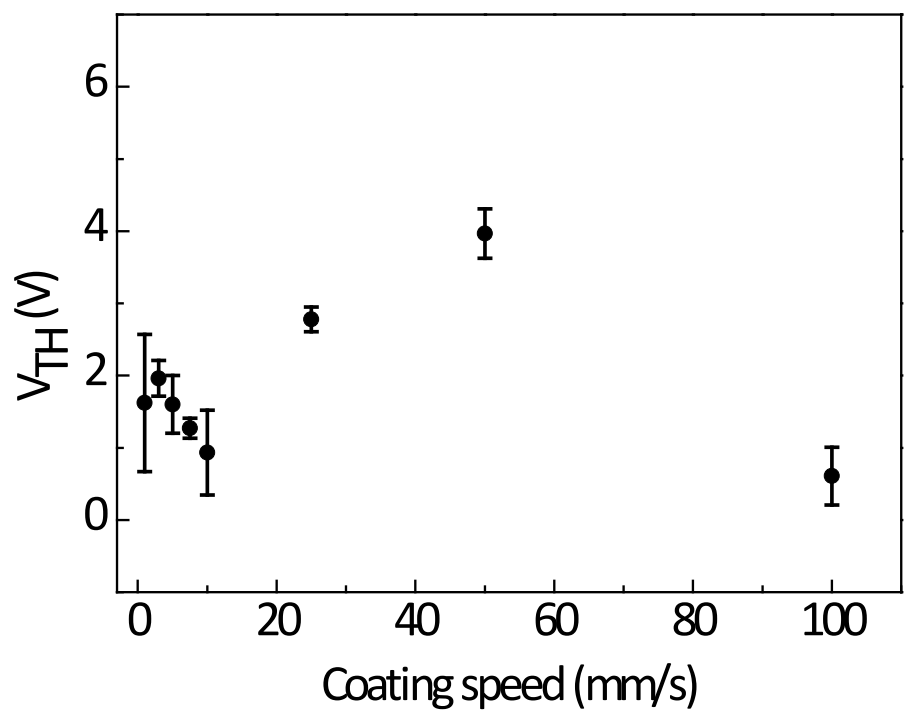

Figure S8. Mean of $V_{T H} v s$ coating speed of OFETs based on DB-TTF/PS. 


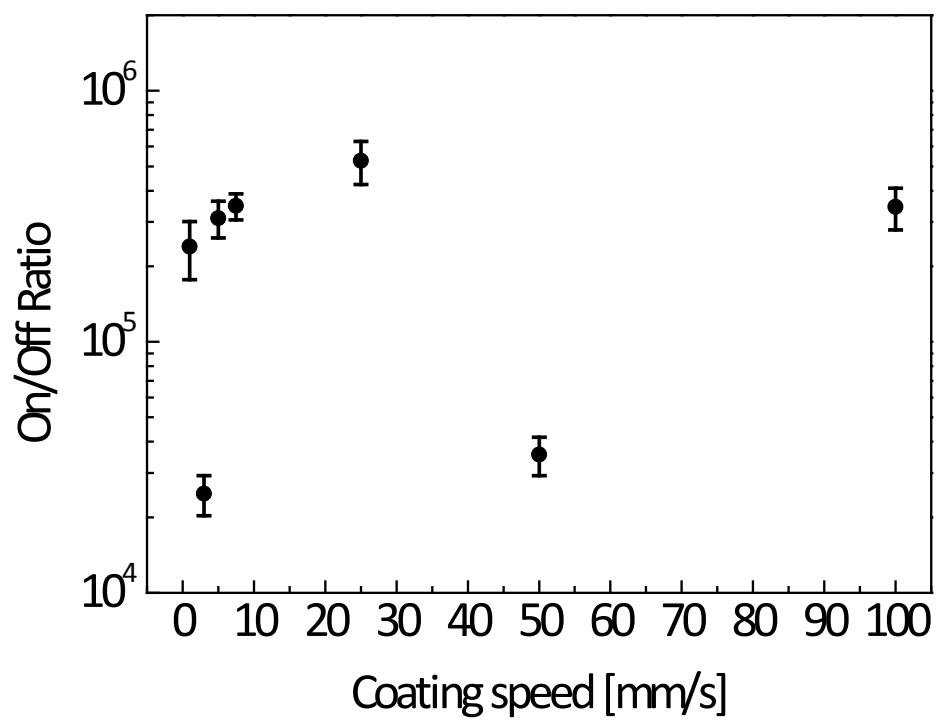

Figure S9. Mean of on-off ratio vs coating speed of OFETs based on DB-TTF/PS.

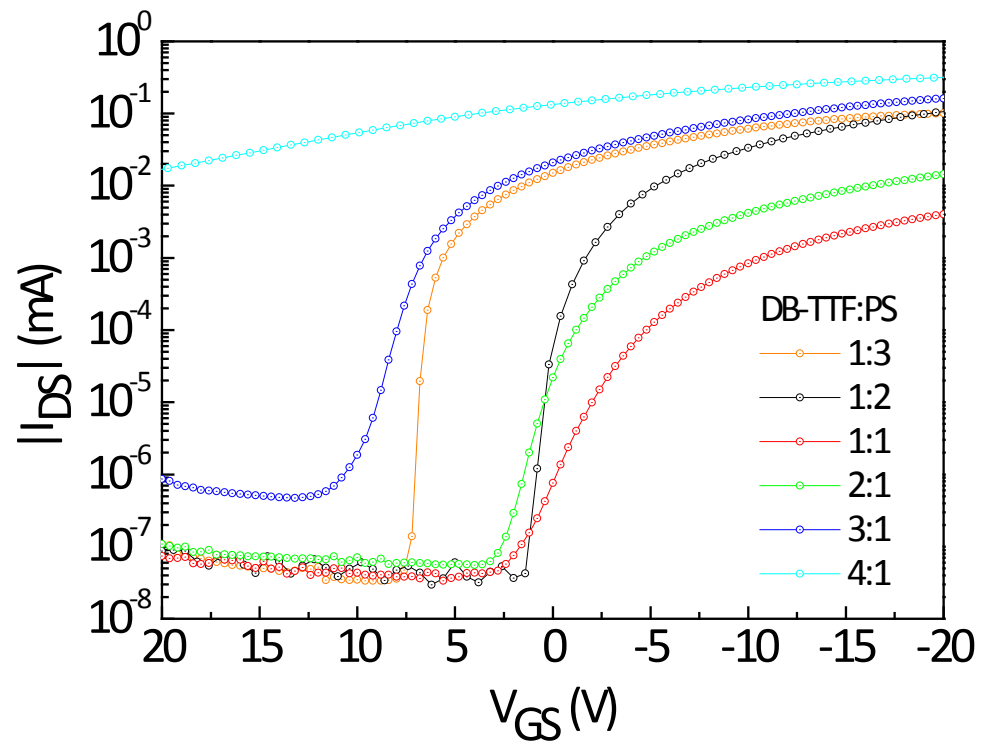

Figure S10. Transfer characteristic of OFETs based on DB-TTF/PS with different ratio. 


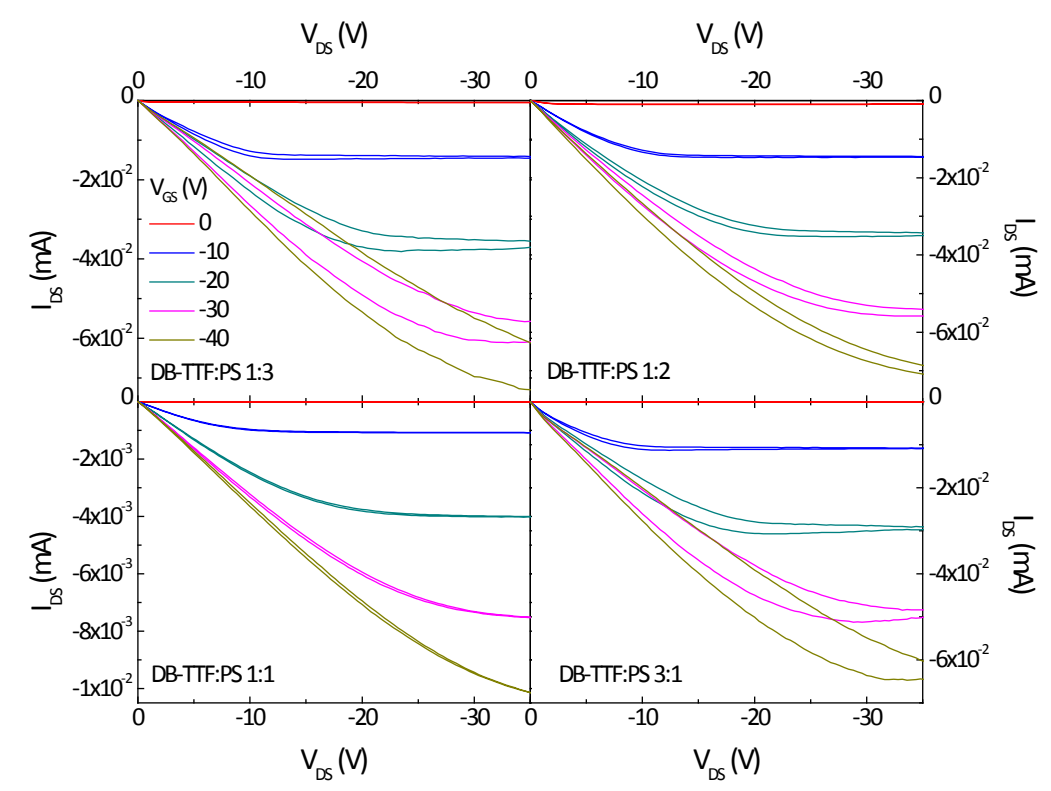

Figure S11. Output characteristic of OFETs based on DB-TTF/PS with different ratio.

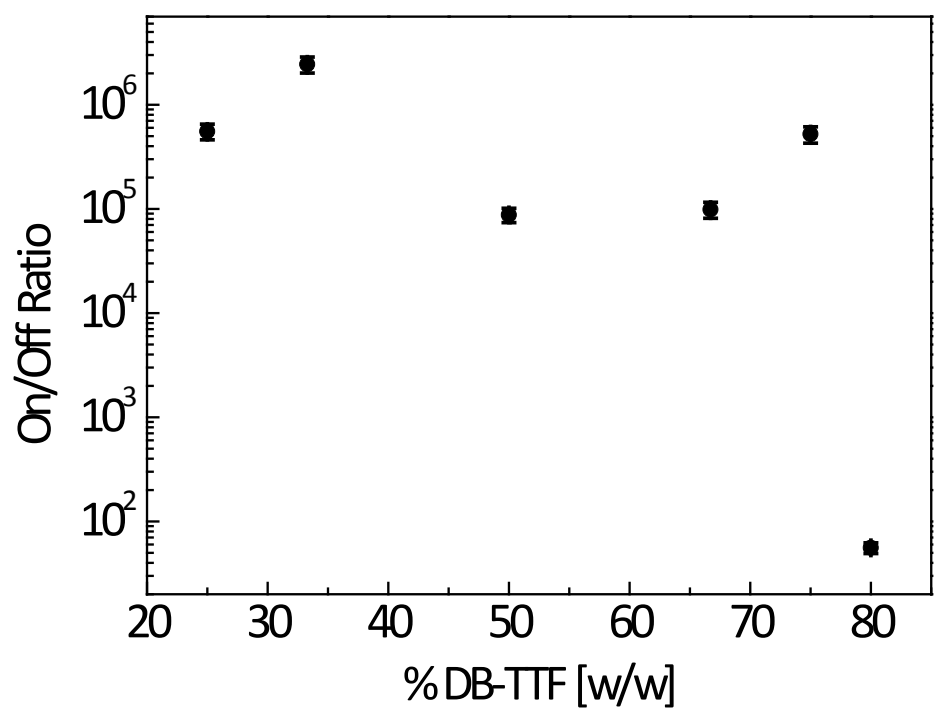

Figure S12. Mean of on-off ratio vs DB-TTF concentration of OFETs based on DB-TTF/PS. 